\title{
Immunisation status in inner London primary schools
}

\author{
H E Bedford, J I Masters, Z Kurtz
}

\begin{abstract}
In one inner London district health authority, the immunisation status of children attending their routine school entry health interview was reviewed over four terms. During the course of these interviews, school nurses completed a questionnaire with parents that asked for their child's immunisation history and details of family and social background. Parental reporting of immunisation history was compared with district health authority records. Only $56 \%$ of children reviewed were found to be fully immunised, although a substantial number (386) of the 513 partially immunised children required only a preschool booster. Four percent (54) of the children had received no immunisations; a disproportionately high number of these were recent immigrants. Mechanisms for identifying unimmunised children before they enter communal groups need to be established.
\end{abstract}

(Arch Dis Child 1992;67:1288-91)

There has been a dramatic improvement in vaccine coverage among 2 year old children over the past decade in this country. This is partly due to initiatives introduced in district health authorities by immunisation coordinators appointed to manage immunisation programmes. ${ }^{1}$ The new target of $95 \%$ coverage ${ }^{2}$ has been achieved by 62 districts for diphtheria and 40 districts for measles vaccine. ${ }^{3}$ There remains a considerable range, however, with lower uptake tending to occur in inner city areas: for example, measles coverage in districts in the South East Thames region ranges between 61 and $95 \% .^{3}$ For target rates to be achieved and maintained in all districts, additional initiatives may be required. Review of children's immunisation status at entry to communal groups such as nurseries, playgroups, and school has been suggested as a mechanism for identifying children who have fallen through the net, with opportunistic immunisation of children found to be inadequately protected who have no parental objection or medical contraindication. ${ }^{4}$

Access to accurate records is necessary to identify unimmunised children but it is well recognised that discrepancies are common between records held by parents, clinics, general practitioners, and health authorities. ${ }^{5-7}$ In inner city areas, with highly mobile populations and many families living in temporary accommodation such as bed and breakfast hotels, maintenance of an accurate child register by the health authority is difficult. ${ }^{8}$

This study was conducted to investigate the feasibility of reviewing children's immunisation status at school entry in an inner London health district, to explore attitudes to the provision of immunisation in schools, and to assess the adequacy of systems used to record immunisation.

\section{Methods}

Over a period of four terms from September 1989 to December 1990, in addition to information routinely collected, school nurses in the 33 primary schools in one inner London health authority completed a questionnaire with parents at each child's school entry health interview. Information obtained included details of immunisation status and whether parents had a written record of their child's immunisations. For those children who were not adequately immunised, the reasons were noted and parents asked whether they would like immunisation to be offered in school. Details of family and social background were gathered including ethnic origin, main language spoken at home, family size, parental occupation, and whether the family was living in temporary accommodation.

Information on each child's immunisation status was subsequently validated by comparison with computerised records held by the district health authority of residence.

In addition, each school nurse was sent a questionnaire in confidence to determine their attitudes to the provision of immunisation in primary schools. Information collected included whether immunisation was currently provided in schools, views on school nurses giving immunisations, and the perceived training needs if they were to provide such a service. Head teachers were also sent a questionnaire to explore their current practice regarding assessment of school entrants' immunisation status and their attitudes to schools adopting a greater role in this area.

\section{Results}

The number of primary school entrants in the district was difficult to establish and is estimated to be 1555 in one year. School rolls are not held at a central point or on computer by the education authority and the school population is constantly changing because of family mobility. Over a period of four terms information was collected for 1411 children at school health interview; two parents refused to take part. Most children $(84 \%, 1053)$ were seen by the school nurse within their first year in school. However, 16\% (199) had been in school for four 
terms or longer, with 12 terms being the longest interval between school entry and the health interview. Forty three percent (87/199) of children who had been in school for four terms or longer had entered an attached nursery class where health interviews are not conducted.

Nine of the 33 head teachers reported having had more than one case of measles, mumps, whooping cough, or rubella among staff or pupils in school during the last academic year.

\section{AGE AND SOCIAL BACKGROUND OF CHILDREN}

Ages of the children at their school health interview ranged from 4.5 to 11 years, although the majority $(69 \%, 981)$ were aged between $4 \cdot 5$ and 6 years. The majority of children were resident in the district under study $(69 \%, 974)$ or the three adjoining health districts $(27 \%$, 377), with the remainder coming from 17 other health districts in London.

Eleven percent of the children (165), were living in temporary bed and breakfast accommodation, $54 \%(89)$ of whom were from the district under study; $21 \%$ (300) of children were from single parent families. Their ethnic backgrounds varied widely: the largest group were white and of UK origin $(32 \%, 446), 27 \%$ (383) were Asian most of whom originated from Bangladesh (84\%, 323), and 12\% (167) were black children, $54 \%(90)$ of whom were of African origin. Thirty four percent (31) of African and 22\% (70) of Bangladeshi children were living in temporary accommodation compared with $5 \%$ (22) of white UK origin. For $39 \%$ (555) of children, English was not the main language spoke at home. Bengali was the main language for the majority of these families $(57 \%$, 314), but 43 other languages were mentioned. An interpreter was available for 205 of the health interviews although in conducting a further 79, the nurses expressed some difficulty with language. Only $1 \%$ (18) of children attended the school health interview unaccompanied by a parent or other adult.

Ninety three percent of children (1318) were reported to be registered with a general practitioner; $2 \%$ (32) were not registered and for a further 61 children this information was not available. Eleven percent (17/153) of children living in temporary accommodation were not registered with a general practitioner compared with $1 \%(15 / 1197)$ of those living in permanent accommodation.

\section{IMMUNISATION STATUS}

Immunisation status was determined on the basis of parental report which for $13 \%$ (189) of children could be verified by a record held by the parents. A further $50 \%$ (705) of parents said they had a record of immunisation but it was not available at the interview; $17 \%$ (241) had no record, and no information was available for $\mathbf{2 7 6}$ children. A health visitor's written summary of preschool health had been received by the school nurses for $38 \%$ (532) of the children.

Immunisation status of the children for diphtheria, pertussis, and measles vaccines is shown in table 1 . Coverage of diphtheria was
Table I Immunisation status as reported by parents for 1411 children. Results are \% (number of children)

\begin{tabular}{llll}
\hline Vaccine & Immunised & Not immunised & Not known \\
\hline $\begin{array}{l}\text { Diphtheria: } \\
\text { Ist }\end{array}$ & $92(1295)$ & $4(56)$ & $4(60)$ \\
3rd & $89(1255)$ & $7(95)$ & $4(61)$ \\
Booster & $67(949)$ & $26(368)$ & $7(94)$ \\
$\begin{array}{l}\text { Pertussis: } \\
\quad \text { lst }\end{array}$ & $78(1100)$ & $17(242)$ & $5(69)$ \\
3rd & $76(1068)$ & $19(272)$ & $5(71)$ \\
Measles & $73(1033)$ & $20(286)$ & $7(92)$ \\
MMR & $43(607)$ & $49(687)$ & $8(117)$ \\
\hline
\end{tabular}

similar to that for tetanus and polio and represents uptake of all three antigens. Overall $80 \%$ were protected against measles having had measles, mumps, and rubella (MMR) and/or measles vaccine.

For the purposes of this study full immunisation was defined as a completed primary course of diphtheria, tetanus, pertussis and polio, protection against measles as either measles vaccine and/or MMR, and a booster of diphtheria, tetanus, and polio. Fifty six percent of children (791) were found to be fully immunised as defined above; $36 \%$ (513) were partially immunised; and $4 \%(54)$ had had no immunisations at all. For the remainder $(4 \%)$, parents either did not know their child's immunisation status (33) or the information provided was not adequate to determine immunisation status (23).

Of the 527 children who were not fully immunised, the majority (368) lacked their preschool booster with 140 children requiring both a booster and protection against measles. The primary course of diphtheria, tetanus, and polio had not been completed by 94 children and 272 were not fully protected against whooping cough, although 30 of these had commenced the course. One hundred and eighty three children lacked protection against measles, having had neither measles vaccine nor MMR combined vaccine.

Asian children were less likely to be fully immunised than other groups; 50 of the 54 children who had no immunisations were of Asian origin. Fifty two percent (48/92) of children living in homeless families' accommodation were fully immunised compared with $60 \%(562 / 932)$ in permanent housing even after allowing for the Asian group. Forty percent of children who were not registered with a general practitioner were fully immunised compared with $60 \%$ of those registered, even after allowing for homeless families.

\section{REASONS FOR INADEQUATE IMMUNISATION}

Differing reasons were given for inadequate immunisations against different diseases: for measles, the most common was that the child was a recent immigrant $(27 \%, 49)$, while 18 parents said they considered the vaccine to be unnecessary because their child had already had the disease. For pertussis, the most common reason given was fear of possible side effects of the vaccine $(13 \%, 36)$. A number of children had not been immunised against pertussis and measles after advice from health professionals. 
Of those children who had had no immunisations, 41 parents gave recent immigration as their reason; a further seven (also immigrant families) said they were unaware of the need for immunisation. Parents of the remaining six, said either that they did not believe in immunisation or were afraid of possible side effects.

Aspects of the service were more likely to be given as the reason for failure to obtain a child's booster injection: an appointment for immunisation had not been received by $17 \%(62)$ of parents. Forty children were delayed in completing their primary course and for $25 \%$ (92) the parents said they had not got round to taking their child for the booster.

Parents of children who were not fully immunised were asked whether they would like their child to be immunised at school; $69 \%$ (317/ 457) were in favour of this, but 89 of the remainder (126) said they would prefer to go to their general practitioner or clinic.

\section{VALIDAFION OF IMMUNISATION STATUS WITH DISTRICT RECORDS}

The immunisation history of each child was checked with records held by their district of residence. No records were available for $40 \%$ (571) of children in the study; this includes older children who may not have been entered onto a computerised system but $30 \%$ of records were not available for children younger than 6 years. Immunisation status could not be validated for a further 19 children as no identifying information had been collected at interview. Records were not available for $50 \%$ of children living in temporary accommodation compared with $39 \%$ of those who were not and for $48 \%$ of Asian children compared with $38 \%$ of children of white UK origin.

Immunisation rates of 821 children for whom a record was available were compared with parental reports and are shown in table 2. Apart from the reporting of MMR vaccine, parents consistently reported higher immunisation rates than districts.

Examination of district records also showed that by three months after their school health interview, 90 children had received further immunisations; the majority of these were MMR and/or boosters.

SCHOOL NURSES' ATTITUDES TO IMMUNISATION Eighty percent $(12 / 15)$ of school nurses

Table 2 Comparison of parents' reports of immunisation rates with district records for 821 children. Results are \% immunised

\begin{tabular}{lll}
\hline Vaccine & $\begin{array}{l}\text { District health } \\
\text { authority } \\
\text { record }\end{array}$ & $\begin{array}{l}\text { Parent } \\
\text { record/recall }\end{array}$ \\
\hline $\begin{array}{l}\text { Diphtheria: } \\
\text { Ist }\end{array}$ & 83 & 97 \\
3rd & 76 & 96 \\
Booster & 68 & 73 \\
Pertussis: & & \\
1st & 71 & 85 \\
3rd & 66 & 83 \\
Measles & 70 & 80 \\
MMR & 53 & 51 \\
\hline
\end{tabular}

responded to the questionnaire. Although eight of the nurses had experience of immunising children, all were generally opposed to immunisation in school; three thought it could be appropriate as a last resort. Reasons given were that it is not good practice and that it is unnecessary because adequate provision already exists. Seven nurses considered that school is not the most appropriate place for immunisation and that it would create problems such as children becoming upset and difficult to settle in class, and would associate school with injections; that it would take up too much time and that there was a lack of adequate facilitites such as for the disposal of waste. Five nurses mentioned that teachers would not wish immunisation to take place in school.

The nurses were not in favour of giving immunisation themselves as they did not perceive it as fulfilling a health education role; six felt it would be detrimental to their relationship with the child. Only three nurses felt adequately trained to give immunisation, and even then would want a doctor on the premises, while seven said they would require a complete practical and theoretical update and four, training on the management of anaphylaxis. Even with appropriate training, eight nurses would not be willing to give immunisation under any circumstances.

HEAD TEACHERS' ATTITUDES TO IMMUNISATION Ninety four percent $(31 / 33)$ of the head teachers responded to the questionnaire. Only two were currently asking parents for details of their child's immunisation status before they entered school and both advised parents of the need for immunisation and how to obtain it if necessary. Of the remaining 29, 20 said they would be prepared to include a question about immunisation in their routine admissions procedure, and 19 to recommend that parents should have their children fully immunised before school entry. Fifteen of the head teachers thought that immunisation should be offered at the school health interview for inadequately protected children, and 16 thought a special immunisation clinic should be provided in school. Head teachers who opposed immunisation in school gave similar reasons to those given by the school nurses: that immunisation is the parents' responsibility, a health and not an educational matter, would cause disruption to classes, and would affect the child's relationship with the school nurse.

\section{Discussion}

The school as a setting is well suited to the production and spread of epidemics. ${ }^{9}$ Children who are not fully immunised on entering school are particularly likely to transmit disease within the school community and also to place younger siblings at risk. Parental reports are likely to be an over estimate of immunisation status, ${ }^{10}$ and particularly inaccurate for older children, ${ }^{11}$ but this study demonstrates that based on parents' reports, a proportion of children entering primary schools in an inner London district are 
inadequately immunised. Based on district figures the proportion not fully protected is even larger. This includes vulnerable children living in homeless families' accommodation where transmission of infection is particularly likely, and children whose families have recently immigrated, often from countries where diseases such as polio and diphtheria are still prevalent. It is of particular concern that $4 \%$ (54) of children had had no immunisations at all; the majority of these parents did not object to immunisation but were unaware of its advisability.

The policy in the district under study is to offer a health interview within the first year of primary school entry and although this was carried out in the majority of cases, a proportion of children were in school for a considerable period before they were seen and their immunisation status assessed, increasing, the likelihood of exposure to infection. Susceptible children need to be identified and immunised before entry to nursery class or primary school in order to prevent outbreaks of disease. This can only be achieved with the cooperation of head teachers and the education authorities. Our findings suggest that many head teachers would be prepared to inquire about immunisation status in their admissions procedure. Such a scheme has proved successful in Tower Hamlets where a growing number of schools include a question about immunisation. ${ }^{12}$

The ability of school nurses to give vaccines on the school premises along with recording of immunisation status has been shown to be critical to the success of programmes aimed at increasing immunisation rates in the school population. ${ }^{13}$ In this study school nurses were found to be reluctant to administer immunisation, but the training of nurses is increasingly encouraged and has been shown to be an important approach in ensuring that hard to reach children are given protection. ${ }^{14}$ If the majority of susceptible children were identified and protected before school entry, school nurses would have to immunise only a small number: those who may have had no previous opportunity and/or reduced access to primary health care services.

Recording of immunisation is still largely inadequate and this study highlights the particular difficulties in inner London. Many districts are now introducing parent held health records as the child's main health record. These have proved to be popular with both parents and health professionals, to be completed accurately, and to be readily available at each health service contact. ${ }^{15}$ National use of these records with standardisation of the immunisation component would facilitate identification of unimmunised children and encourage opportunistic immunisation. It is important that all health professionals involved in immunisation are aware that completing a record of vaccines given is an essential part of the immunisation procedure. Reliability and completeness of records and accurate evaluation of vaccine coverage would be improved if standard procedures were established for relaying data to the core information system within districts. Increasing population mobility also necessitates compatibility of systems for transfer of data between districts.

The aim is to ensure that children are protected from infectious disease as early as possible and the recently introduced accelerated immunisation schedule has been a contributory factor in improving vaccine coverage among young children. ${ }^{1}$ However, if childhood infectious diseases are to be eliminated, mechanisms for identifying unprotected children, such as review of immunisation status at school entry, must be established.

This study was funded by Action Research to whom we are indebted. Thanks also to the school nurses and parents involved in the study.

1 Gillam SJ, Begg NT. The COVER scheme: a survey of immunisation coordinators. Communicable Disease Repor 1991;1:R88-9.

Department of Health. The health of the nation. London: HMSO, 1991 .

3 White JM, Hobday SJ, Begg NT. 'COVER' (cover of vaccination evaluated rapidly: 20 . Communicable Disease veport 1992;2:R12.

4 Peckham C, Bedford H, Senturia Y, Ades A. National immunisation study: factors influencing immunisation uptake in childhood. Horsham: Action Research for the Crippled Child, 1989.

5 Jefferies S, McShane S, Oerton J, Victor CR, Beardow R. Low immunization uptake rates in an inner-city health district: fact or fiction? $\mathcal{f}$ Public Health Med 1991;13 312-7.

6 Rawson NSB, Alderslade R, Miller DL. Discrepancies in immunization records. Community Medicine 1980;2:202-8.

7 Pennington E, Wilcox RML. Immunization, practice record and the white paper. $\mathcal{F} R$ Coll Gen Pract 1988;38:515-6.

8 Begg NT, White JM. A survey of pre-school vaccination programmes in England and Wales. Community Medicine 1988;10:344-50

9 Joseph C, Noah N, White J, Hoskins T. A review of outbreaks of infectious disease in schools in England and outbreaks of infectious disease in schools in Englan

10 Hawe P, Wilson A, Fahey P, et al. The validity of parental report of vaccination as a measure of a child's immunisation report of vaccination as a measure of

status. Med 7 Aust 1991;155:681-6.
11 Rawson NSB. Plus ca change, plus c'est la meme chose J Public Health Med 1991;13:342.

12 Hertogs D. Tower Hamlets health authority measles immunisation initiative 1987-88. Public Health 1989;103:421-6.

13 DeAngelis C, Berman B, Oda D, Meeker R. Achieving optimal immunization levels in school-age children. fPediatr 1983;103:811-

14 Jefferson N, Sleight G, MacFarlane A. Immunisation of children without a doctor present. BMF 1987;294:423-4.

15 Saffin K, MacFarlane A. How well are parent held records kept and completed? Br f Gen Pract 1991;41:239-51. 